\title{
A STUDY OF THE STRONG GROUND MOTION OF THE BORREGO MOUNTAIN, CALIFORNIA, EARTHQUAKE
}

\author{
By Thomas H. Heaton and Donald V. Helmberger
}

\section{ABSTRACT}

Several synthetic models are constructed to fit the first $40 \mathrm{sec}$ of the transversely polarized displacement, as recorded at El Centro, of the April 9, 1968 Borrego Mountain earthquake. The modeling is done in the time domain using the response computed for a distributed set of point shear dislocations embedded in a layered half-space. The beginning $10 \mathrm{sec}$ of the observed record is used to model the spatial and temporal distribution of faulting whereas the remaining portion is used to determine the upper crustal structure based on surface-wave periodicity. A natural depth criterion was provided by comparing the amplitude of the direct arrival with the surface-wave excitations. Trade-offs are found to exist between source models and velocity structure models. Within the framework of a layer over a half-space model, faulting of finite vertical extent is required, whereas the horizontal dimensions of faulting are not resolvable. A model which is also consistent with the teleseismic results of Burdick and Mellman indicates massive faulting near a depth of $9 \mathrm{~km}$ with a fast rise time producing a $10 \mathrm{~cm}$ displacement pulse of $1 \mathrm{sec}$ duration at El Centro. The faulting appears to slow down approaching the surface. The moment is calculated to be approximately $7 \times 10^{25}$ dyne-cm which is somewhat smaller than the moment found by Burdick and Mellman (1976).

\section{INTRODUCTION}

Understanding the nature of strong ground motion is a problem of importance to both seismologists and earthquake engineers. Generally, the engineering community has been particularly interested in the shorter periods whereas the former investigators usually study the more coherent longer-period motions. However, in recent times their domains of interest appear to overlap in the frequency band from 0.1 to $10 \mathrm{~Hz}$ because man-made structures have become larger and because seismologists have become increasingly interested in the details of faulting that can only be obtained from a combination of teleseismic and local observations. In many situations, the seismic waves recorded in the local field travel more nearly horizontal paths than waves which are recorded at teleseismic distances. This allows us to sample waves from earthquakes $\tilde{w}$ hich leave the source area in directions which are inaccessible to researchers studying the wave forms of teleseismic records. Unfortunately, the fact that energy in the $I_{1}$ : al field travels nearly horizontal paths implies that reflections from horizontal crustal layers are both large and complicated. In the local field, a clear distinction between body waves and surface waves is not possible. Thus, in many respects, interpreting the relative effects of source and earth structure is a more tractable problem for teleseismic modeling than for local field modeling. Yet, as we will show in this paper, it is possible to model local observations of earthquakes with realistic source and crustal structure models. Obviously, it is important to construct earthquake source models which are compatible with both local and teleseismic wave forms. This test of compatibility is especially important with respect to the assumed $Q$ structure of the Earth which must be used when correcting teleseismic observations. Thus, the 
inclusion of local observations into the data set in earthquake studies is becoming increasingly important.

In most previous wave-form modeling of strong ground motion, researchers have circumvented the complications of horizontal layering by considering only records which are taken very close to the causative fault. Most studies of this nature approximate the earth response by the response of a homogeneous whole space with an amplitude correction of two in order to approximate the free surface. Since only direct waves can be generated by such a model, simple source models will result in relatively simple pulse-like wave forms. Unfortunately, strong ground motion records displaying simple pulse-like wave forms are relatively rare. Some of the better examples are: (1) the Pacoima Dam recording of the 1971 San Fernando earthquake which has been modeled by Trifunac (1974), (2) the Cholame no. 2 recording of the 1966 Parkfield earthquake modeled by Aki (1968), Trifunac and Udwadia (1974), Kawasaki (1974), and Anderson (1974). Anderson and Richards (1975) have reviewed several of the different source models which have been used in modeling such records and they give some insight into the ambiguities which are present in modeling ground motion very close to an earthquake. They demonstrate that a variety of source models with quite different rupture motions, rupture geometries, rupture velocities, and rise times can produce very similar near-field motions in a homogeneous whole space. Things change considerably when horizontal layering is introduced into the problem. If the structure is not known, even greater ambiguity in source modeling exists due to the introduction of more variables. Things may not be as hopeless as they first appear though, since if the structure is known its effects can be used to advantage. That is, the response of a layered medium is unlike that of a homogeneous medium in that the response of the layered medium is a sensitive function of the position of the source within the layers. Thus if the structure is known, the complications due to that structure can help clear up ambiguities concerning the source. Consider the dilemma presented by any single displacement record taken in a homogeneous whole space. It is practically impossible to distinguish a source composed of several point dislocations from another source which consists of only one point dislocation. This ambiguity is not as severe in a layered space since each of the several point sources will interact with the structure in a predictable fashion. A case will be made that the El Centro record of the Borrego Mountain earthquake cannot be adequately modeled with just one point dislocation. This distinction could not be made for homogeneous whole-space models.

\section{The Borrego Mountain Earthquake}

The Borrego Mountain earthquake occurred at 2:29 GMT on April 9, 1968 and has been assigned a magnitude of 6.4 (Allen and Nordquist, 1972). A surf ace rupture which extended nearly $31 \mathrm{~km}$ was recognized along three well-defined zones of fracture (north, central, and south segments) which comprise the Coyote Creek fault which is itself a segment of the San Jacinto fault zone of southern California. A maximum right-lateral offset of $38 \mathrm{~cm}$ was measured along the north segment and rightlateral offsets of 25 to $30 \mathrm{~cm}$ and 8 to $14 \mathrm{~cm}$ were measured on the central and south segments, respectively (Clark, 1972). The central and south segments are distinguished from the north segment in that approximately half the displacements measured were recognized to be due to post earthquake creep (Burford, 1972). Surface ruptures of 1 to $2 \frac{1}{2} \mathrm{~cm}$ were also reported by Allen et al. (1972) for segments of the Superstition Hills, Imperial, and San Andreas faults. These displacements are presumed to be due 
to fault creep which was triggered by the Borrego Mountain earthquake. Figure 1 shows the spatial relationship of these various faults. Rupture appears to have initiated on the north segment. Aftershocks define a diffuse zone which is about $50 \mathrm{~km}$ in length (Allen and Nordquist, 1972). No conspicuous increase in seismicity could be found for the Superstition Hills, Imperial and San Andreas faults.

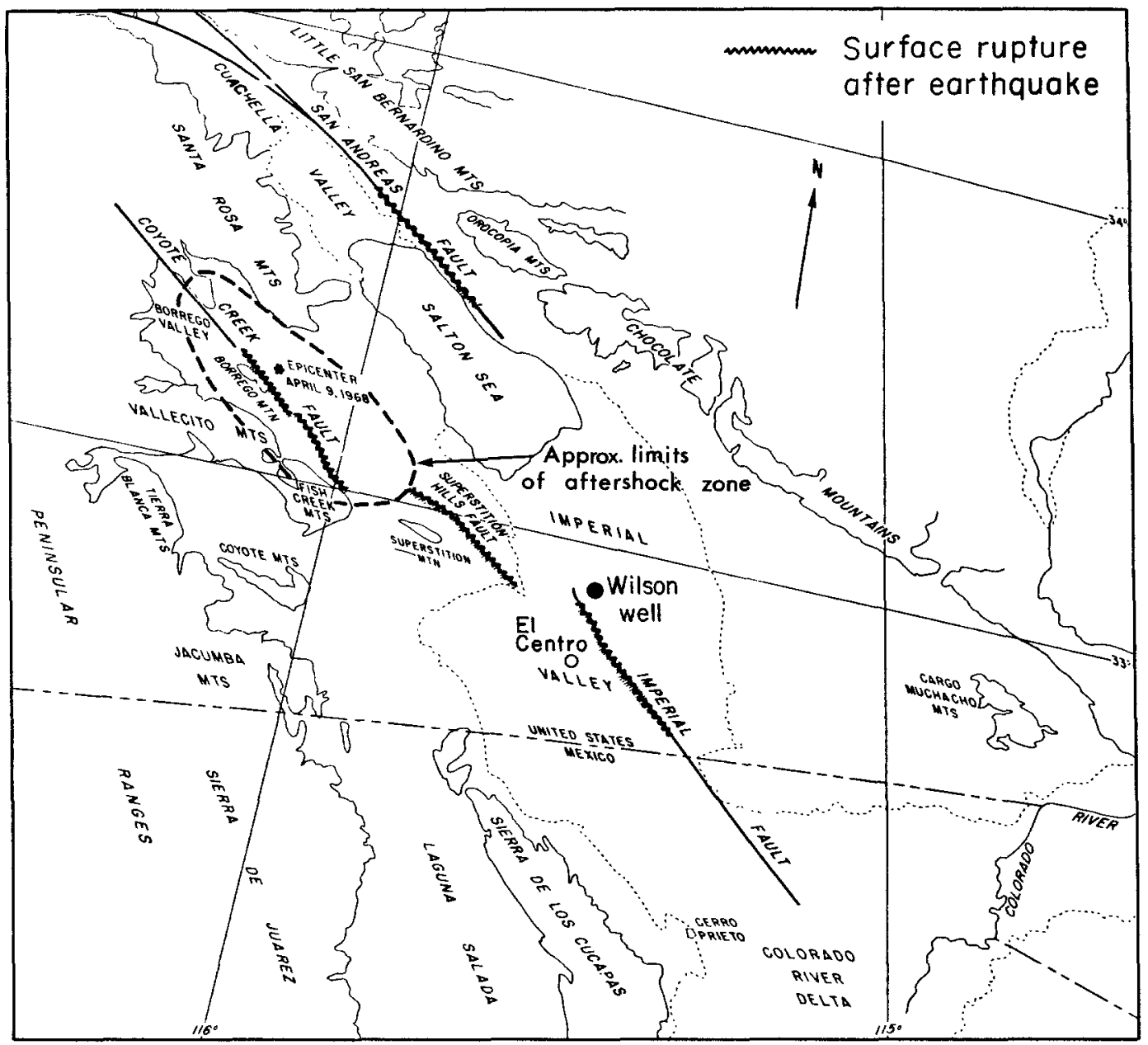

Fig. 1. Oblique map of the Salton Trough. Jagged lines indicate segments of faults that moved in association with the 1968 Borrego Mountain earthquake. The distance between meridians shown is $93.5 \mathrm{~km}$ along the $33^{\circ} \mathrm{N}$ parallel (Figure modified from U.S. Geol. Survey Profess. Paper 787).

Faulting on the north segment of the Coyote Creek fault displays several features which clearly distinguish it from other fault segments which had rupture associated with the earthquake. Both the initiation of rupturing and the largest offsets occurred on the north segment. As compared with the central and south segment, the north segment had fewer aftershocks and very little postseismic creep. Burdick and Mellman (1976) argue pursuasively that these variations in the behavior of the fault segments reflect different behaviors deep in the Earth. Their modeling of teleseismic wave forms seems to require a short duration source time function and hence a small source 
dimension. They suggest a circular fault of radius $8 \mathrm{~km}$. If indeed such a small source area is required, then clearly the north segment is the likely candidate.

\section{The El Centro Strong Ground-Motion Record}

The Borrego Mountain Earthquake triggered 114 strong-motion seismographs in southern California and southeastern Nevada (U.S. Coast and Geodetic Survey et $a l ., 1968)$. Most of the instruments were located in the Los Angeles area which is approximately $200 \mathrm{~km}$ from the epicentral region. The closest strong-motion stations were located at El Centro, San Diego, and Perris Dam which are at epicentral distances of 60,100 , and $120 \mathrm{~km}$, respectively. We chose to model only the El Centro recording because it was the closest station and was the only station located in the same geologic province (the Salton Trough) as the earthquake. Moreover, Carder displacement meters were located at El Centro, providing reliable information at periods beyond 8 sec.

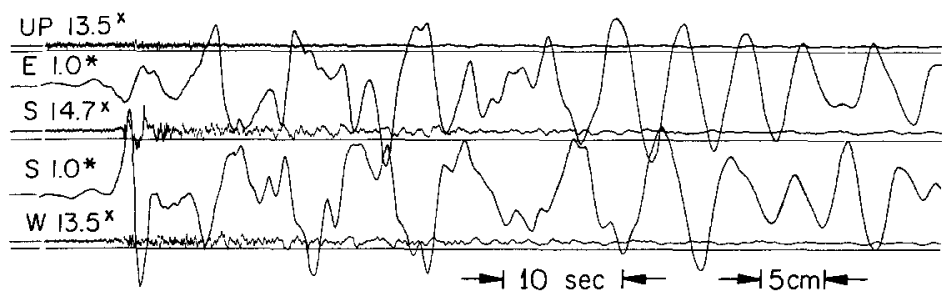

(x) Sensitivity in $\mathrm{cm} / \mathrm{g}$; (*) Static magnification.

Fig. 2. El Centro accelerograph and Carder displacement-meter record from the Borrego Mountain earthquake (U.S. Coast and Geodetic Survey et al., 1968).

Figure 2 shows both displacement records as well as accelerograph records from El Centro. The accelerograph records have been integrated to obtain both ground velocity and displacement (Hudson et al., 1971). Figure 3 shows that the ground motion obtained by double integration compares favorably with the ground motion obtained by deconvolution of the instrument response from the Carder displacement meter records. The Carder instruments have free periods of $6.4 \mathrm{sec}$ on the $\mathrm{E}-\mathrm{W}$ component and $6.8 \mathrm{sec}$ on the N-S component. The deconvolved Carder records have been heavily filtered at periods beyond 14 sec with an Ormsby type filter to avoid the inherent instability present in the deconvolution process. We believe that the deconvolved Carder record gives a very reliable representation of the ground motion at El Centro. The agreement between the integrated accelerogram and the deconvolved Carder record is remarkable when one realizes that the free periods of the accelerographs are about 0.067 sec. However, there does appear to be significant disagreement in the absolute amplitude scales. This discrepancy raises questions about the reliability of the gains reported for these instruments.

El Centro is only $8^{\circ}$ from being directly along the strike of the earthquake fault plane. Since the earthquake was strike-slip along a vertical fault, we expect to be very close to an $S H$ radiation maximum and $S V$ and $P$ radiation nodes. The tangentially polarized, radially polarized, and vertical components of ground motion are also shown in Figure 3. The vertical component is a doubly integrated accelerogram (Hudson et al., 1971). The horizontal components were rotated such that the azimuth of the tangential and radial axes were $\mathrm{S} 37^{\circ} \mathrm{W}$ and $\mathrm{S} 53^{\circ} \mathrm{E}$, respectively. The first 40 sec of displacement are dominated by transversely polarized motion as indicated in 
Figure 3c. Considerable radially polarized motion is present in the next 40 sec of ground motion. One possibility is that this departure from transverse polarization is due to lateral reflections of surface waves in the Salton Trough.

\section{Crustal Structure in the Salton Trough}

The Salton Trough is a structural depression which is the northward continuation of the Gulf of California. This depression is underlain and bounded by Mesozoic and older crystalline rocks. As much as $6 \mathrm{~km}$ of upper Tertiary and Quaternary marine and nonmarine sediments fill this depression. Also present in the Salton Trough are several major active right lateral fault zones, recent volcanism, and potential geo-

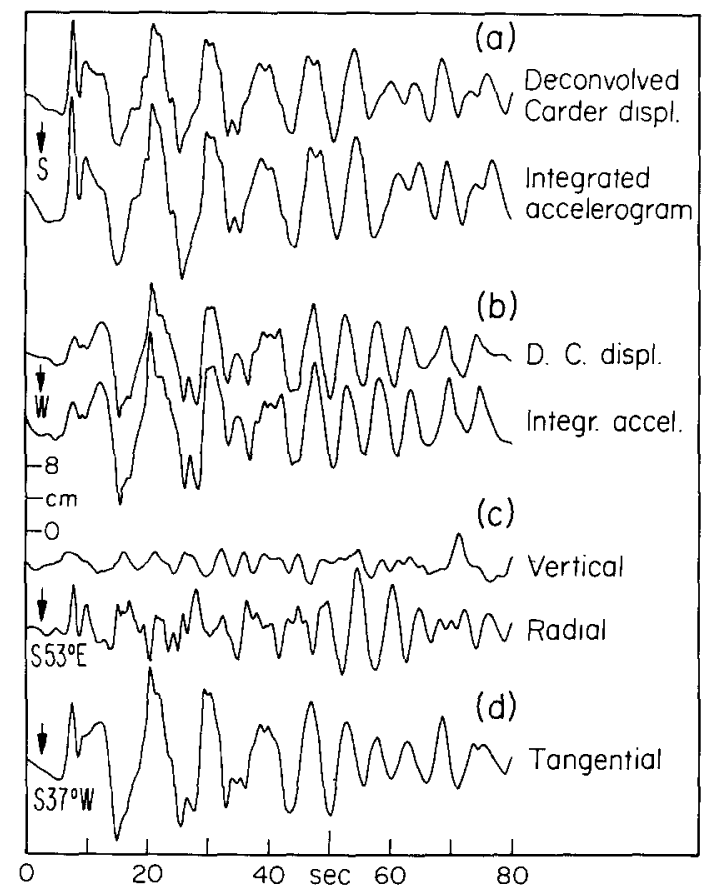

FIG. 3. Summary of observed ground motion. (a) Comparison of deconvolved Carder displacement meter record and integrated accelerogram for N-S component. (b) Comparison of deconvolved Carder displacement meter record and integrated accelerogram for $\mathrm{E}-\mathrm{W}$ component. (c) Ground motion rotated into vertical, radial, and tangential components.

thermal reserves. The Borrego Mountain earthquake occurred along the western side of the trough whereas El Centro lies close to the axis of the depression. The work of Biehler (1964) and Hamilton (1970) indicates that considerable variation in upper crustal velocity structure exists along the path from Borrego to El Centro. A summary of the crustal structure found by Hamilton (1970) for the Borrego vicinity is given in Table 1. Also in Table 1 is the uppermost crustal structure reported by Biehler (1964) for his closest refraction line to El Centro. Clearly, the thick layer of sediments underlying El Centro is not present in the epicentral region. In fact, basement rocks are exposed in the Superstition Hills which lie $20 \mathrm{~km}$ from El Centro and along the line between the epicenter and El Centro. Fortunately, the basin structure near El Centro consists of relatively flat, laterally homogeneous sediments. Experience has shown us that the major effect of sediments is to allow postcritical angle multiple reflections to occur in the section. Furthermore, for a source beneath the sediments, reflection 
points for these multiple reflections occur near the receiver. Since our modeling technique is limited to plane layers, it is important that our structure model give a fair representation of the receiver sediment structure rather than the sediment structure at the source. For our purposes, we found that it was sufficient to model the sedimentary stack with only one low-velocity surface layer. Although modeling the complicated upper crustal structure from Borrego to El Centro with a simple plane layer over a half-space does not seem entirely satisfying, it should be realized that this model retains the essential characteristic in that it traps $S H$ waves in the upper layer. We believe that the Imperial Valley sediments also trap $S H$ waves and that their response is approximated by that of a layer over a half-space. This approximation probably

TABLE 1

(A) Crustal Structere in the Epicentral Region As Reported by Hamilton (1970)

\begin{tabular}{ccc}
\hline Layer & $\begin{array}{c}\text { Compressional-Wave } \\
\text { Velocity }(\mathrm{km} / \mathrm{sec})\end{array}$ & Depth to Top (km) \\
\hline 1 & 2.5 & 0.0 \\
2 & 5.1 & 0.4 \\
3 & 6.0 & 2.9 \\
4 & 7.1 & 14.0 \\
5 & $7.9 ?$ & $25.0 ?$ \\
\hline
\end{tabular}

(B) Upper Crustal Structure as Reported by Biemler (1964) for the Wilson et al. Well.*

\begin{tabular}{ccc}
\hline Layer & $\begin{array}{c}\text { Compressional-Wave } \\
\text { Velocity }(\mathrm{km} / \mathrm{sec})\end{array}$ & Depth to Top (km) \\
\hline 1 & 1.9 & 0.0 \\
2 & 2.1 & 0.4 \\
3 & 2.6 & 1.0 \\
4 & 3.7 & 2.0 \\
5 & 4.7 & 3.4 \\
6 & 6.4 & 6.0 \\
\hline
\end{tabular}

* Shown in Figure 1

becomes progressively worse for shorter-period waves. Finally, it should be pointed out that we chose the layer velocity and thickness such that it fit the observed Love waves. Even though this layer thickness and velocity was not determined directly from refraction profiles such as Biehler's (1964), we feel that our model is compatible with the inferred depth of sediments in the Imperial Valley.

Because of the pcssibility of head waves and reflection of downgoing rays, intermediate and deep crustal structure can have a significant effect on the beginning portion of the strong ground-motion record. Hamilton (1970) has suggested that compressional-wave velocities as high as $7.1 \mathrm{~km} / \mathrm{sec}$ exist as shallow as $14 \mathrm{~km}$ and that the moho may be only $25 \mathrm{~km}$ deep in this region. As will be seen later, it is not necessary to include intermediate and lower crustal structure in order to model the EI Centro strong-motion record. Thus we will mainly concern ourselves with a structure model which consists of a simple layer over a half-space. However, due to the possibility of relatively shallow high-velocity layers, a structural model which includes these layers will also be considered. 


\section{Response of Shear Dislocations in a Layered Half-Space}

One of the most fundamental concepts in the method which we have used in this study is the notion of the response of a layered half-space to a point shear dislocation. Obviously an earthquake is not a point dislocation, but for our purposes it is often very difficult to distinguish a point dislocation from a fault of finite dimension. We will discuss the relationship between finite fault models and point dislocation models in more detail later. The method we have used to find the point dislocation response is the generalized ray method. The solution is represented by the sum of the responses of individual generalized rays, each of which traverses a different ray path that is characterized by the interfaces it contacts. In general, an infinite number of rays are necessary to give an exact representation of the solution. The number of rays necessary for a close approximation is a function of the source and receiver geometry in relation to a given structure. Fewer than 20 generalized rays were necessary to approximate the response of a $3-\mathrm{km}$ layer over a half-space at a range of $60 \mathrm{~km}$. The response of each generalized ray was computed by using the Cagniard-de Hoop technique. This technique allows us to compute how a wave form is distorted as it propagates through the various layers. It differs from simple geometrical ray theory in that it includes diffraction effects such as head waves.

The complete solution containing both the near-field and the far-field terms for dislocation sources embedded in a layered half-space has been discussed by Helmberger (1974) and Vered and Ben-Menahem (1974). For the periods and station ranges of interest in this study, it is sufficient to model only the far-field terms so that asymptotic solutions can be used (see Helmberger and Malone, 1975). The time history of dislocation at a point is included by simply convolving the time history with the medium response. Trial and error was used to fit the actual record by taking combinations of distributed dislocation sources with proposed crustal structures.

\section{Modeling with A Single Point Source}

The first models which we will consider will be those consisting of a single point source. These models allow us to investigate the effect of structure in a fairly direct way. Figure 4 illustrates the step function response of a point source located at various depths within a layer over a half-space model. The upper layer's thickness and velocity have been defined such that they fit the long-period Love waves as recorded at El Centro. Theoretical ground motions are obtained by convolving the derivative of the step-function response with the far-field time function of the source. The particle motion of the point dislocation is the integral of the far-field time function. For shallower source depths, the direct wave is diffracted by the shallow layer and becomes less distinct and at the same time, Love waves are strongly developed. When the source is placed in the upper layer, the first arrivals are head waves with later arrivals being high-frequency critical reflections which are trapped in the upper layer. We see no evidence of these high-frequency critical reflections in the El Centro record and thus our sources will always be located beneath the surface layer. This conclusion is supported by the fact that the sediments directly above the earthquake are thin and also by the hypocentral depth of $8 \mathrm{~km}$ computed by Burdick and Mellman (1976).

Model B42, shown in Figure 5, is the ground motion which one expects for a point source with a simple triangular far-field time function which is located at a depth of $6 \mathrm{~km}$ in the layer over a half-space model. It does a fair job of fitting the Love waves, but does poorly for the first large $S H$ pulse which is present on the record. We next 
investigated the possibility that the first $S H$ pulse was actually due to a diving ray. By adding high-velocity lower crustal layers it is possible to obtain near-critical angle reflections which introduce sharp pulses to the beginning of the synthetic and which have virtually no effect on the Love-wave portion of the synthetic record. Model B67

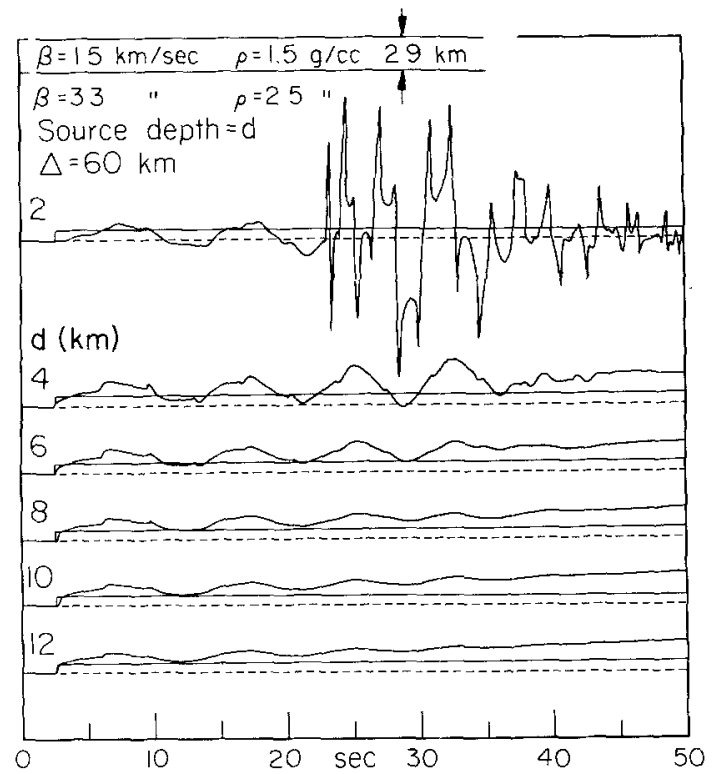

FIG. 4. $S H$ step function response at the surface assuming a point strike-slip dislocation located at various depths. The amplitudes are scaled in relation to the top trace with the step response for a homogeneous half-space displayed for comparison.

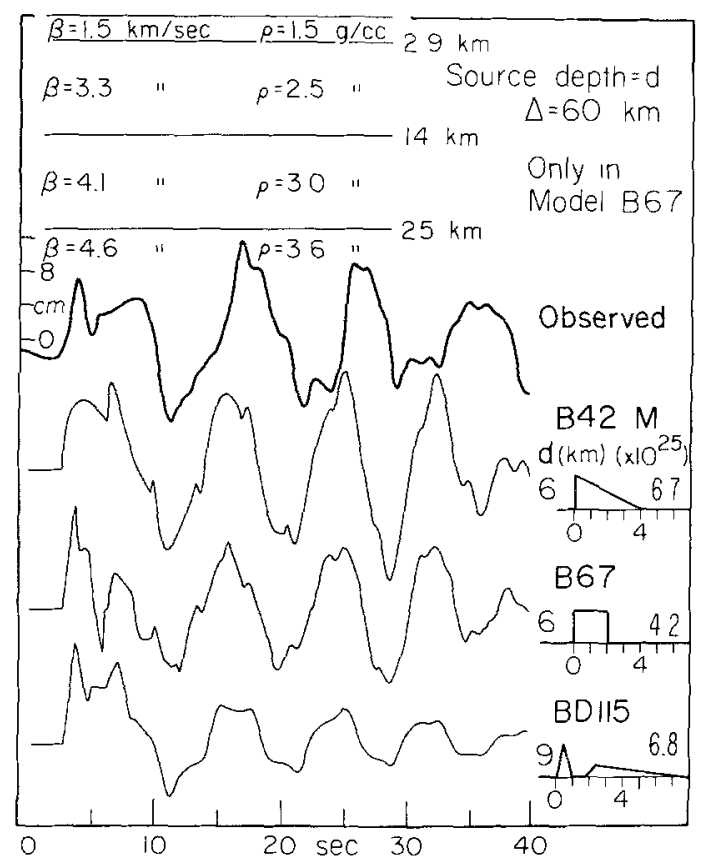

FIG. 5. Comparison of observed with synthetic $S H$ ground motion for models consisting of a single point dislocation source. Far-field source time functions are displayed on the right. Deep crustal layers were included in model B67 whereas a simple layer over a half-space was used for models $\mathrm{B} 42$ and BD115. 
which is shown in Figure 5, is the result of an attempt to model the first $S H$ pulse with a diving ray. It matches the first pulse well, but does poorly on the broad second pulse. High shear wave velocities seem to be required at depths less than $20 \mathrm{~km}$ by such models. Even though Hamilton's work (1970) suggests a moho at $25 \mathrm{~km}$, the velocity model for B67 seems somewhat extreme. Although we are not entirely comfortable with the high velocities of model B67 and even though other models will be presented which fit the record better, we believe that a diving ray could well be an important contributor to the sharp pulse at the record's beginning. The advantage of model $\mathrm{B} 67$ is that a very simple point-source time function is all that is necessary to produce both sharp body waves and a well-developed Love wave. All other models which will be presented in this study will consist of a simple layer over a half-space model, but will require more complex sources to fit both body waves and Love waves.

Model BD 115, which is shown in Figure 5, is an example of a layer over a halfspace with a point source which has a complicated time function. Since the source is relatively deep at $9 \mathrm{~km}$, the direct shear wave is sharp and thus it was possible to model the first $10 \mathrm{sec}$ well. Because of the depth, though, the Love wave is too small. This motivated us to investigate models with both a deep source and a shallow source.

\section{Modeling with Two Point Sovrces}

In the previous section we discussed the notion of fitting the Love waves with a fairly shallow source and then we invoked reflections from deeper layers to explain the sharp first arrivals. An alternative approach is to have a shallow source which produces mainly Love waves and a deep source which produces sharp body waves. We chose to model the record with a source at $9 \mathrm{~km}$ and another source at $4 \mathrm{~km}$. Furthermore, we allowed these sources to have different time histories. Because of the large number of variables which are introduced into this model, it is not surprising that the record could be fit quite well. Figure 6 illustrates four of the models which gave good fits. These models vary in detail, but a common feature is a sharp time function for the deep source and a slower time function for the shallow source. The total moments for all these models seems to be approximately $7 \times 10^{25}$ dyne-cm.

It seems fairly important to ask whether or not the models shown in Figure 6 are consistent with the teleseismic observations of the Borrego Mountain earthquake. Burdick and Mellman's (1976) inversion of teleseismic body waves for source parameters yielded a moment of $1.12 \times 10^{26}$ dyne-cm which is somewhat larger than that of our two-source models. Our computed moment would be on the order of $10^{2 i}$ dyne$\mathrm{cm}$ if the integrated accelerograms were used in place of the Carder records. This is due to the previously mentioned discrepancy in amplitude found between integratedaccelerogram and displacement-meter records. It should also be noted that Hanks, Hileman, and Thatcher (1975) reported a moment of $6 \times 10^{25}$ dyne-cm for the Borrego Mt. earthquake based on a combination of body-wave spectra, isoseismal maps, and extent of surface faulting.

Burdick and Mellman (1976) were also able to isolate the phase $s P$ and then simultaneously deconvolve short- and long-period recordings of $s P$. From this procedure they obtained a detailed source time function appropriate for the phase $s P$. Figure 7 shows the $s P$ time functions that would be predicted by our two-source models. Model BD116 agrees very well with the observed teleseismic $s P$ time function. Model BD116 is thus very appealing in that it fits the El Centro strong $S H$ ground motion and it is also consistent with the teleseismic observations. Unfortunately, it is rather obvious that the Borrego Mountain earthquake was not two point dislocations. How are we 


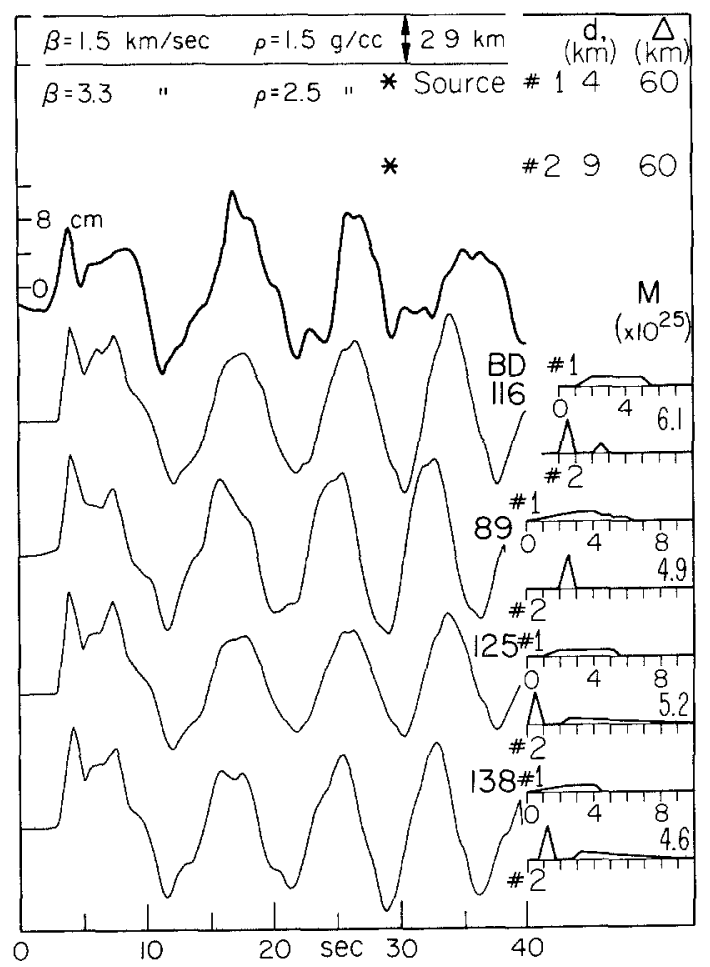

Fig. 6. Comparison of observed with synthetic $S H$ ground motion for models consisting of two point-dislocation sources embedded in a half-space overlain by a single layer. Both shallow and deep far-field source time functions are displayed on the right.

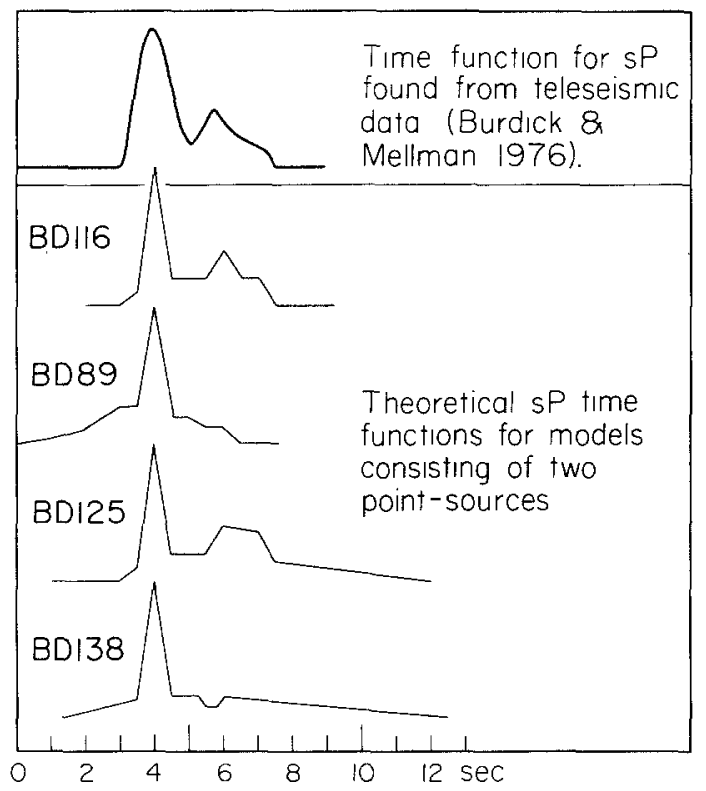

Frg. 7. Comparison of teleseismic $s P$ time function reported by Burdick and Mellman (1976) with $s P$ time functions computed for our models consisting of two point sources. 
to relate model BD116 to the slip which occurred along the Coyote Creek fault? We'll delay a closer examination of this question until the discussion section of this paper.

\section{Modeling with Finite Sources}

In the previous section we have shown that it is possible to construct a relatively simple model which is consistent with the teleseismic recording and also the EI Centro strong ground motion. Our main concern was to fit the seismic data and we gave relatively little consideration to our intuition that these seismic waves were due to an offest along a two-dimensional surface which we call the Coyote Creek fault. Let us try a different approach in which we build several simple models of what we, a priori, think the earthquake should look like. We chose to model the earthquake as a radially

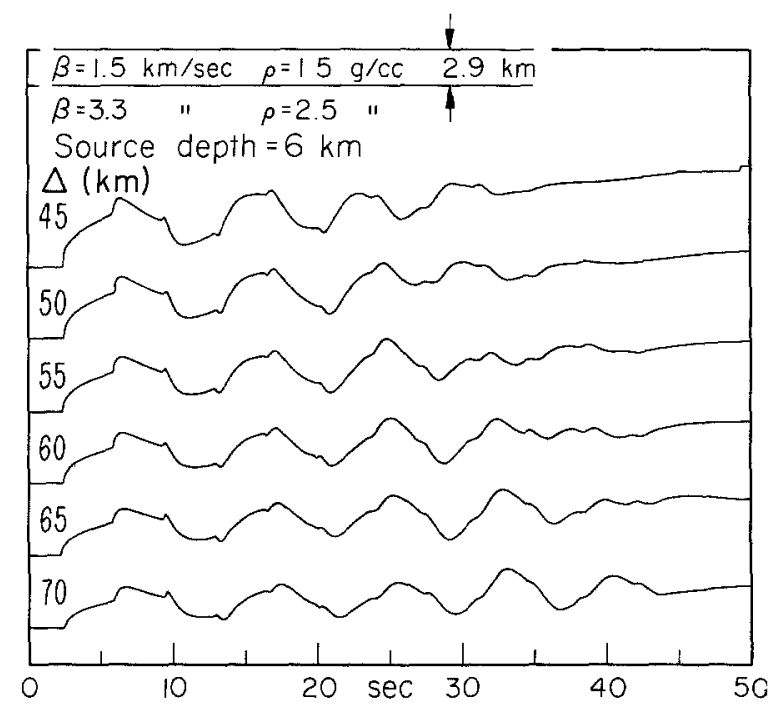

FIG. 8. SH step function response as a function of distance and the constant depth of $6 \mathrm{~km}$. The fact that the response changes very little with distance means that it is virtually impossible to resolve the difference between a horizontal line source and a point source convolved with the appropriate time function.

propagating, uniform dislocation which is confined to a vertical rectangular surface. Because of the success we had with the point-source models, we retained the layer over a half-space structure which was used in those models. Since we have no analytical expression for the point-source response of this structure model, it was not possible to analytically integrate the infinitesimal point-source response over the fault plane. Instead, each square kilometer of fault surface was approximated by a point dislocation source. Figure 8 shows that the step-function response is a slowly varying function of range. Generalized ray theory was therefore used to compute only the response functions of sources which were spaced at intervals of $5 \mathrm{~km}$ horizontally and $2 \mathrm{~km}$ vertically. The remaining response functions were computed by simply interpolating between the response functions found by generalized rays. Response functions were then added with an appropriate time delay which was a function of only the rupture velocity and fault geometry. This sum of response functions is then convolved with a source time function which is the time derivative of the particle motion on the fault plane. Particle motion is assumed to be uniform everywhere on the fault plane. Dis- 
placements in a homogeneous whole space have been analytically determined by Savage (1966) for similar types of fault models.

In Figure 9, synthetics are shown for an $11-\mathrm{km}$ by 5 -km rectangular fault with different hypocentral locations and rupture velocities. BNOR1 is a model in which the rupture begins at the center of the rectangle and propagates radially with a rupture velocity of $2.5 \mathrm{~km} / \mathrm{sec}$. A triangular source time function was used and convolu-

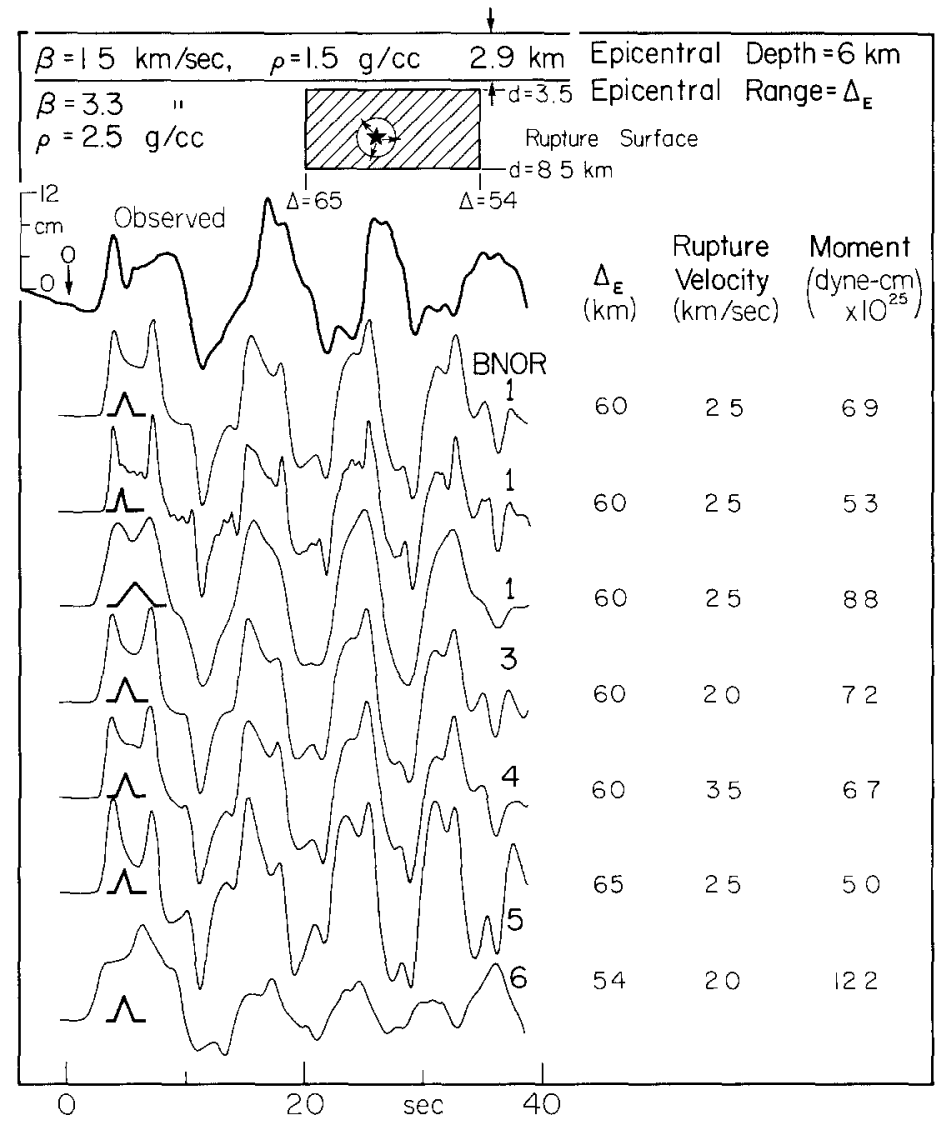

FIG. 9. Comparison of observed with synthetic $S H$ ground motion for models consisting of a rectangular fault with uniform offset which initiates at a point and propagates radially to the edge of the rectangle. In models BNOR5 and BNOR6 the rupture propagates unilaterally toward and away from El Centro, respectively. Rupture propagation is bilateral in the other models shown. The far-field time function for each point on the fault is displayed directly beneath the beginning of each synthetic.

tions of BNOR1 with triangles of durations of $3.0,1.5$, and 0.75 sec are shown in Figure 9. The 1.5-sec triangle clearly gave a superior fit and we have convolved this 1.5-sec triangle with our other finite fault models. BNOR3 and BNOR4 which are also seen in Figure 9 are identical to BNOR1 except that the rupture velocities were 2.0 and $3.5 \mathrm{~km} / \mathrm{sec}$, respectively. The synthetics do not appear to be very sensitive to the rupture velocity for this size fault. Finally, Figure 9 shows BNOR5 and BNOR6 which are identical to BNOR1 except that rupture initiates on the far and near ends of the fault, respectively.

Model BNOR1 does a very respectable job of fitting the El Centro ground motion; 
particularly the character of the Love wave. This success is encouraging and we believe that it should be possible to construct a relatively simple finite source model which would fit the data just as well as our two-point source model. Model BNOR1 yielded a moment of $7 \times 10^{25} \mathrm{dyne} \mathrm{cm}$. This would indicate an offset of about $500 \mathrm{~cm}$ and a stress drop which is near 500 bars. These estimates seem very large indeed. Figure 10 illustrates our attempts to decrease the fault offset by increasing the fault area. BNOR7 has a fault which is $26 \mathrm{~km}$ long by $9 \mathrm{~km}$ deep. Even with this much larger fault, the calculated offset would be about $110 \mathrm{~cm}$, whereas the largest observed surface offset was only $38 \mathrm{~cm}$. Moreover, BNOR7 has the problem that its body waves are too large compared to the Love waves. This can be alleviated by making

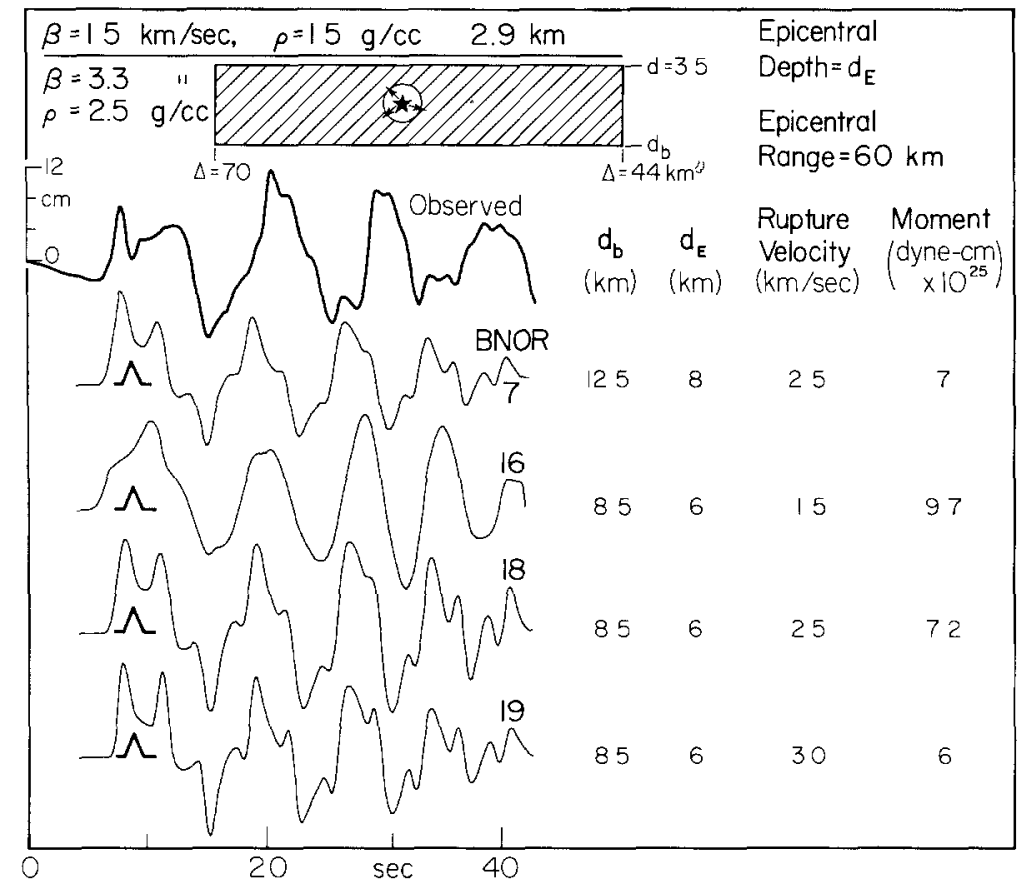

FIG. 10. Comparison of observed with synthetic $S H$ ground motion for models consisting of a rectangular fault as described in Figure 8 except with a larger fault area. Notice that the direct arrival for BNOR7 is too large in relation to the Love wave. This situation is alleviated by making the fault-plane shallower.

the fault shallower. $A$ fault which is $26 \mathrm{~km}$ long by $5 \mathrm{~km}$ deep was used in BNOR18 and BNOR19 which had rupture velocities of 2.5 and $3.0 \mathrm{~km} / \mathrm{sec}$, respectively. These models fit the actual record adequately, but the fault offsets must grow to about 200 $\mathrm{cm}$. Part of this dilemma which we have encountered is due to the fact that we have not allowed the rupture to extend into the soft sediment layer because of the highfrequency reflections which our model will produce. In reality though, the sediments above the earthquake are probably very thin and discontinuous with the sedimentary stack at El Centro. Furthermore, we know that the earthquake ruptured clear to the surface. Yet our plane layer model does not allow us to model the contributions of the very shallow section of the fault plane. If we were able to model the upper $3 \mathrm{~km}$ of rupture, then we could also allow the fault to extend to depths below $10 \mathrm{~km}$ without disturbing the ratio of body-wave to Love-wave amplitudes. 
We have not drawn many conclusions regarding the earthquake from our attempts to model the El Centro record with a finite source. There does not appear to be enough information to resolve important parameters such as fault dimensions, rupture velocity, and time history. What we have demonstrated is that it is possible to adequately fit the El Centro strong-ground motion with simple finite source models embedded in a layer over a half-space structure model.

\section{Discussion}

It appears that the El Centro record can be successfully modeled by both finite source models and also by models which consist of only two point sources. Is it posw sible to reconcile these different types of sources? If we were dealing with a homogeneous space, then it is obvious that it would be impossible to resolve the difference between a finite source and a point source with just one record. We could simply modify the time function for the point source such that it fit a single recording of any finite source. In general, this would not be true if we had to fit several recordings of the same event. The introduction of velocity structure is analogous to having several recordings of the earthquake in that the study of the interaction of seismic waves with the layers allows us to determine where those waves originated with respect to the layers. Figure 4 illustrates that it would be possible to resolve the difference between a vertical line source and a single point source for the case of a layer over a half-space. This is because the response changes with depth. Figure 8 shows that the response changes very little with the horizontal distance of the source (for our geometry). Thus it is very difficult for us to resolve the epicentral distance of a point source. In fact, it is virtually impossible for us to tell the difference between a point source and a finite horizontal line source. Thus the response of a finite vertical rectangular fault plane can be approximated by a vertical line source with an appropriate time function. In our case the response of the vertical line source is approximated by two point sources of different depth.

\section{Conclusions}

The strong ground motion recorded at El Centro for the 1968 Borrego Mountain earthquake is dominated by $S H$ type motion. Displacements of up to $13 \mathrm{~cm}$ are indicated by the rotated deconvolved Carder displacement-meter records. The thick sedimentary layer present in the vicinity of El Centro is modeled by a single $2.9 \mathrm{~km}$ thick layer. This layer traps $S H$ waves allowing the formation of Love waves. In reality, there is considerable heterogeneity in the sediment structure along the path from the earthquake to $\mathrm{El}$ Centro, but the Love waves are formed in the flat-lying sediments relatively near El Centro.

It is possible to model the El Centro record with a single point source if relatively shallow high-velocity lower crustal layers are introduced. If a simple layer over a half-space model is used, at least two point sources are necessary to provide an adequate fit to the record. Within the framework of this structure model, it appears to be possible to show that the majority of faulting extended from the free surface to a depth of not more than $12 \mathrm{~km}$. A sharp time function with a 1-sec duration is indicated for the deeper segment at the fault, and a slower time function with a duration of greater than $4 \mathrm{sec}$ is implied for the shallow parts of the fault. The horizontal dimension of the faulting does not appear to be resolvable. Considerable nonuniqueness is present in the models constructed and parameters such as fault geometry, hypo- 
center, rupture velocity, and rise time do not appear to be resolvable. A model which is consistent with the teleseismic study done by Burdick and Mellman was demonstrated. The earthquake moment was found to be approximately $7 \times 10^{25}$ dyne-cm.

\section{ACKNOWLEDGMENT}

We wish to thank G. Mellman, H. Kanamori, and C. Langston for critically reading the manuscript. We also would like to thank the California Institute of Technology, EERL, and G. Brady of the U.S. Geological Survey for allowing us access to the original strong-motion record.

This research was supported by the Advanced Research Projects Agency of the Department of Defense and was monitored by the Air Force Office of Scientific Research under Contract F4462072-C-0083 and by National Science Foundation ENV76-10506.

\section{REFERENCES}

Aki, K. (1968). Seismic displacements near a fault, J. Geophys. Res., 73, 5359-5376.

Allen, C. R. et al. (1972). Displacements on the Imperial, Superstition Hills, and San Andreas faults triggered by the Borrego Mountain earthquake, U.S. Geol. Surv. Profess. Paper 78\%, $87-104$.

Allen, C. R. and J. M. Nordquist (1972). Foreshock, main shock and larger aftershocks of the Borrego Mountain earthquake, U.S. Geol. Surv. Profess. Paper 787, 16-23.

Anderson, J. (1974). A dislocation model for the Parkfield earthquake, Bull. Seism. Soc. Am. 64, $671-686$.

Anderson, J. G. and P. G. Richards (1975). Comparison of strong ground motion from several dislocation models, Geophys. J. 42, 347-373.

Biehler, S. (1964). Geophysical study of the Salton Trough of southern California, Ph.D. Thesis, California Institute of Technology, Pasadena.

Burdick, L. J. and G. R. Mellman (1976). Inversion of the body waves from the Borrego Mountain earthquake to the source mechanism, Bull. Seism. Soc. Am. 66, 1485-1499.

Burford, R. O. (1972). Continued slip on the Coyote Creek fault after the Borrego Mountain earthquake, U.S. Geol. Surv. Profess. Paper 787, 105-111.

Clark, M. M. (1972). Surface ruptures along the Coyote Creek fault, U.S. Geol. Surv. Profess. Paper 787, 55-86.

Hamilton, R. M. (1970). Time-term analysis of explosion data from the vicinity of the Borrego Mountain, California, earthquake of April, 9, 1968, Bull. Seism. Soc. Am. 60, 367-381.

Hanks, T. C., J. A. Hileman, and W. Thateher (1975). Seismic moments of the larger earthquakes of the Southern California region, Bull. Geol. Soc. America 86, 1131-1139.

Helmberger, D. V. (1974). Generalized ray theory for shear dislocations, Bull. Seism. Soc. Am. 64, $45-64$.

Helmberger, D. V. and S. D. Malone (1975). Modeling local earthquakes as shear dislocations in a layered half-space, $J$. Geophys. Res. 80, 4881-4888.

Hudson, D. E., A. G. Brady, M. D. Trifunac, and A. Vijayaraghavan (1971). Strong-motion earthquake accelerograms, corrected accelerograms and integrated velocity and displacement curves, Vol. II, Part A, Earthquake Eng. Res. Lab., EERL 86-88, California Institute of Technology, Pasadena, California.

Kawasaki, I. (1975). On the dynamical process of the Parkfield earthquake of June 28, 1966, $J$. Phys. Earth (Tokyo) 23, 127-144.

Savage, J. C. (1966). Radiation from a realistic model of faulting, Bull. Seism. Soc. Am. 56, 577592.

Trifunac, M. D. (1974). A three-dimensional dislocation model for the San Fernando, California, earthquake of February 9, 1971, Bull. Seism. Soc. Am. 64, 149-172.

Trifunae, M. D. and F. E. Udwadia (1974). Parkfield, California earthquake of June 27, 1966: A three-dimensional moving dislocation, Bull. Seism. Soc. Am. 64, 511-533.

U.S. Coast and Geodetic Survey, Seismological Field Survey, and California Institute of Technology, Earthquake Engineering Research Laboratory (1968). Strong-Motion instrumental data on the Borrego Mountain earthquake of 9 April 1968, San Francisco, California, 119 pp.

Vered, M. and A. Ben-Menahem (1974). Application of synthetic seismograms to the study of 
the low-magnitude earthquakes and crustal structure in the northern Red Sea region, Bull. Seism. Soc. Am. 64, 1221-1237.

Seismologtcal Laboratory

California Institute of Technology

Pasadena, California 91125

Division of Geological and Planetary Sciences Contribution No. 2769

Manuscript received June 10, 1976 